\title{
A POINT OF VIEW ON THE PERCEPTION OF FUTURE PROFESSIONALS ON ENERGY EFFICIENCY OF REFIRGERATION SYSTEMS
}

\author{
Ionela Ticu $^{1}$, Elena Gogu ${ }^{2}$ \\ ${ }^{1}$ Constanta Maritime University, Faculty of Naval Electro-Mechanics, 104 Mircea cel Batran Street, 900663, Constanta, \\ Romania, e-mail address: ionela.ticu@yahoo.com \\ ${ }^{2}$ Gheorghe Duca" Technological High School, Vifor Haiducul Street, No 34, Constanta, Romania, e-mail address: \\ goguelena@yahoo.com
}

\begin{abstract}
In the modern times, energy efficiency is of high interest because there is direct link between this concept and energy conservation, economics, environment and sustainable development. The energy efficiency intensification at international level is closely follow by national leaders and worldwide governments and organisations and by top companies as well. Considering this obvious aspects, higher education institutions are deeply involved in involving energy efficiency in the curricula of future professionals, in order to allow them to gain skills that will help in solving challenges specific to this activity. In this international context, Constanta Maritime University introduced in the curricula of the students enrolled in the specialization called Engineering and Environment Protection in Industry a discipline dealing with this very important activity, named Thermal Efficiency of Buildings and Industrial Processes. This paper is investigating the manner in which our students have mastered the tools of energy efficiency assessment of refrigeration systems, throughout a questionnaire applied to them, at the end of the chapter dedicated to these technologies. The students had to write short comments to very specific questions. Analysis of the comments helps the lecturer and the students to take appropriate measures in the next future. Thus, the feedback resulted to be quite positive because most of the students gained the knowledge provided in this respect. Still, delicate concepts, such as entropy, exergy or exergy destruction seem to raise difficulties to some students. In this respect, results that such an intermediary assessment has to be repeated more often, for other kind of technologies discussed during this course, with the involvement of the concepts introduced by the second law- which are essential in energy efficiency assessments.

Key words: energy, efficiency, thermal, industrial, processes, refrigeration, questionnaire, entropy, exergy, destruction.
\end{abstract}

\section{INTRODUCTION}

In the present times, humanity is facing the fast diminishing of traditional energy resources, the wise use if the existing ones being of capital importance. Since the energy systems are so much present in all our activities, their sustainable operation is an important priority for all scientists. Having in view the new concepts, such as public health, environmental friendly economy and sustainable development, scientists have to approach very carefully the assessment of energy systems- that are issue of continuous innovation in order to reach energy conservation [1]. On the other hand, there is a need in reducing costs specific to the energy consumption, as well. These aspects can be easily achieved throughout rising awareness of future engineers in respect with the management of operations, equipment, devices and energy strategies that will be met during their future activity [2].
In this framework, it is obvious the fact that in technical universities should be implemented adequate educative curriculum materials, able to challenge not only the teaching stuff, but mostly the future professionals, in order to achieve skills, competencies and engineering creativity. Energy Educative Materials have many specific features and lead to important outcomes [3]:

features:

- elevate energy vocabulary;

- understanding of complex situations, concepts, writings;

- continuation of the findings;

- providing of a wider literature survey;

- improved interaction between expert and future professional;

- subtle approach of energy issues;

- easier access to best practices; 
- access to powerful engineering assessment tools; opening to new developments;

- insurance of long lasting and reliable materials. outcomes:

- student facile understanding;

- diminished wrong understanding of fundamentals;

- easier approach of initially difficult seen topics;

- attractive teaching process;

- better integration between theoretical and practical teaching activities;

- boost of research activities;

- closeness to energy issues in a more creative manner;

- easier understanding of energy practices and policies.

Every day life cannot be accepted without refrigeration, technology met in the preservation and transport of perishable or in providing thermal comfort, but which is known to be a large energy consumer [4]. Refrigeration is introduced in the curricula of the discipline entitled Thermal Efficiency of Buildings and Industrial Processes, Year 3, Second Semester, for students enrolled in Engineering and Environment Protection in Industry specialization, in Constanta Maritime University-ROMANIA. In accordance with the above mentioned, within this course treats very seriously the energy efficiency issue, as well. In the time table of the curricula, for these kind of system are allocated $6 \mathrm{~h}$ for theoretical and practice activities. Energy Educative Materials reflecting energy efficiency of refrigeration plants, provided to the students are based on the following pylons [5], [6]:

1. selection of refrigerants: focusing on environmental regulations- expresses by the research on new refrigerants having a zero Ozone Depletion Potential (ODP)and low Global Warming Potential (GWP);

2. selection of the cycle: in the case in which the refrigerants has a high GWP it is needed the adoption of an other cooling system (indirect cooling) with the use of a brine;

3. selection of the working parameters - when it is seen that increase of evaporation and condensation temperatures are affecting the performance of the cycle;

4. adequate thermal insulation of refrigeration rooms and optimum heat balances - based on the fact that limited insulation of the cooled rooms is reflected in the limitation of load capacity, so that it is required the isolation improvement;

5. selection of refrigeration component parts: detailed by compressor selection has to be done so that maximum cooling production is fulfilled at pick needs; it is recommended the adoption of counter flow condenserheat exchanger in which will happen the cooling (in the first quarter), the condensation (in the following two quarters) and sub cooling of the liquid refrigerant; the evaporator has to has fins and needs periodic defrosting;
6. exploitation: are given the steps of the efficient exploitation:

- planning the exploitation;

- respect procedures;

- trained stuff;

- monitories the performance;

- upgraded automation;

- update of the plant.

This paper deals with the discussion of a questionnaire submitted to the students mentioned above, in order to have a perspective of the knowledge gained specific to energy efficiency of refrigeration technology. Initially, during the teaching process, students were acquainted with the above written concepts. Also, they have been trained to understand and to use the mathematical formulation of the performance analysis- provided in the following section. The content of the questionnaire and the interpretation of the feedbacks will be analysed in the following.

\section{METHODS AND MATERIALS}

In Figure 1 one can see the cycle of an vapour compression refrigeration system (VCRS) with its main components: evaporator, compressor, condenser, throttling valve; the cycle is the simples one- meaning with no superheating and no sub cooling.

According their curricula, future engineers are trained to know that a viable analysis cannot be obtained only by the use of the first law equations, because exergy analysis allows the assessment of the maximum performance of the system and the finding of the places with exergy destruction. Thus, such a themodynamic analysis should involve formulas specific to the first and second laws.

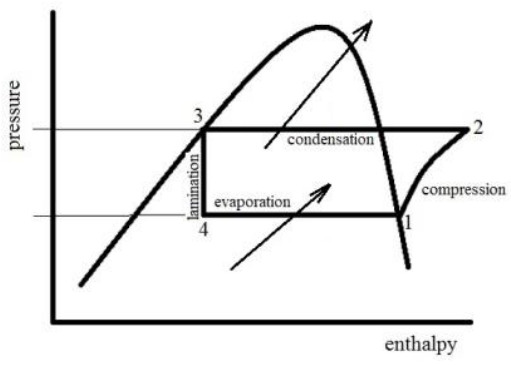

Figure 1 Simpliest cycle of VCRS with specific processes.

For the evaporator are written formulas for the heat load and exergy losses, as given in equations (1) and (2):

$$
Q_{e}=q_{m}\left(i_{1}-i_{4}\right)
$$

here:

$$
\mathrm{q}_{\mathrm{m}}-\text { mass flow, }(\mathrm{kg} / \mathrm{s})
$$




$$
\text { Exe }_{e}=q_{m}\left(\text { exe }_{4}-\text { exe }_{1}\right)+Q_{e}\left(1-\frac{T a}{T_{e}}\right)
$$

$(\mathrm{kJ} / \mathrm{kg})$

here:

$$
\begin{aligned}
& \text { exe }- \text { specific exergy, }(\mathrm{kJ} / \mathrm{kg}) \\
& \text { exe }=\left(\mathrm{h}-\mathrm{h}_{\mathrm{a}}\right)-\mathrm{T}_{\mathrm{a}}\left(\mathrm{s}-\mathrm{s}_{\mathrm{a}}\right) \\
& \mathrm{T}_{\mathrm{a}}-\text { surrounding ambiant temperature, }(\mathrm{K}) \\
& \mathrm{T}_{\mathrm{e}}-\text { evaporation temperature, }(\mathrm{K}) \\
& \mathrm{s}-\text { specific entropy, }(\mathrm{kJ} / \mathrm{KgK})
\end{aligned}
$$

The amount of work need to the compressor it is calculated with equation (3):

$$
W_{c}=q_{m}\left(i_{2}-i_{1}\right)
$$

While the exergy losses in the compressor is as given by equation (4):

$$
\text { Exe }_{c}=q_{m}\left(\text { exe }_{1}-\text { exe }_{2}\right)+W_{e l}
$$

here:

$$
\begin{aligned}
& \mathrm{W}_{\mathrm{el}}-\text { compressors electrical power, }(\mathrm{kJ}) \\
& W_{e l}=\frac{W_{c}}{\eta_{m} \cdot \eta_{e l}} \\
& \eta_{\mathrm{m}}-\text { mechanical efficiency } \\
& \eta_{\mathrm{el}}-\text { electrical efficiency }
\end{aligned}
$$

For the condenser, it is possible to write equations for its load- equation (5) and exergy loss formula (6):

$$
\begin{gathered}
Q_{c d}=q_{m}\left(i_{2}-i_{3}\right) \\
\text { Exe }_{c d}=q_{m}\left(\text { exe }_{2}-\text { exe }_{3}\right)-Q_{c d}\left(1-\frac{T_{a}}{T_{c}}\right)
\end{gathered}
$$

here:

$$
\mathrm{T}_{\mathrm{c}}-\text { is the condensation temperature, }(\mathrm{K})
$$

When passing to the throttling valve, the exergy destruction has the form as in equation (7):

$$
\operatorname{Exe}_{T V}=q_{m}\left(\text { exe }_{4}-\text { exe }_{3}\right)
$$

Accorging to the Law 1, the performance is given by the The Coefficient of Performance, written as in equation (8):

$$
C O P=\frac{Q_{e}}{W_{e l}}
$$

While exergy losses, as a whole, are estimated as in equation (9):

$$
\operatorname{Exe}_{0}=\operatorname{Exe}_{e}+\operatorname{Exe}_{c}+\operatorname{Exe}_{c d}+\operatorname{Exe}_{T V}
$$

As stated, this material will not be limited to the theory of Law 1 of thermodynamics, so that it is given also the exergy efficiency as in equation (10):

$$
\eta_{e x e}=\frac{E x e_{1}-E x e_{4}}{W_{e l}}
$$

According to the results from the literature, as seen in [7], [8], when the evaporation temperature increases and the condensation temperature is constant are obtained the following:

- the specific work input increases;

- the Coefficient of Performance increases;

- the specific exergy loss in the compressor increases:

- the specific exergy loss in the throttling valve decreases;

- the specific exergy loss in the condenser decreases;

- the specific exergy loss in the evaporator decreases;

- the exergy efficiency increases.

The energy efficiency questionnaire on refrigeration issues was addressed to 32 students. The aim was to help the lecturer and the students, as well, to find out if this concept is familiar enough to the students, at the end of the chapter dedicated to this technology.

The structure of the questionnaire is given below. The students were asked to write answers in the form of short commnets.

1. In your opinion, which is the most suitable refrigerant to be used in the existing plants?

2. What is the challenge of existing plants in the case of the natural refrigerants use?

3. Which is the most important benefit of the Hydrofluorocarbons (HFCs)?

4. What can you say on the pressures of the refrigerant?

5. What is the effect of evaporation temperature increase on the Coefficient of Performance?

6. Which principle is introducing concepts as entropy and exergy?

7. How can you, briefly, define the entropy?

8. Which is the connection between evaporation temperature increase and irreversibilities?

9. Why increases the exergy efficiency of the refrigeration system together with the increase of the evaporation temperature?

10. Which is the situation in which the plant works at its best energy efficiency?

\section{RESULTS AND DISCUSSIONS}

Question 1: the situation results as follows- $100 \%$ of the students replied that the acceptable refrigerants are the one showing low GWP. The answer is correct, since in the light of Kyoto Protocol, the industry is pushed to adopt eco-friendly refrigerants, such as Hydrocarbons, in order to solve the global warming issue. 
Question 2: 100\% of the students replied that the challenge consist in adapting the plant structure to the properties of the new refrigerant.

Question 3: $100 \%$ of the students replied that HCFs do not contain Chlorine in their formula, this is why they do not affect the ozone layer.

Question 4: refrigerants pressure should allow their work with acceptable sizes for pipes and compressors. $10 \%$ of the students replied considering their working pressures, while $80 \%$ comments stated that the evaporation pressure should be low and the condensation pressure should be high; the rest of the comments stated that there should be a pressure difference between the low and high side of the plant.

Question 5:70\% of the answers say that COP is increasing together with the increase of the evaporation temperature, but only $65 \%$ continue with the explanation: this is due to the fact that the refrigeration effect is increasing; $10 \%$ replied that the pressure ratio decreases, while $20 \%$ didn't answer.

Question 6: $72 \%$ of the answers stated that these two concepts are introduced throughout the second principle pf thermodynamics, $16 \%$ of the comments contain the fact that entropy is introduced by the first law and exergy is introduced by the second law; $9 \%$ included the both parameters in the theory of the first law, while $3 \%$ couldn't answer at all.

Question 7: Entropy is a measure of randomness or disorder within a process. $81 \%$ of the comments say that entropy is a thermodynamic parameter- without any additional specifications, in $11 \%$ cases was seen a confusion between entropy and enthalpy (11\% gave the definition for enthalpy), while $8 \%$ was not able to offer any answer/ comment.

Question 8: The rise of evaporation temperature leads to the irreversibility decrease. $84 \%$ of the students are aware of the fact that real process are irrevesibile, so that their comments refer to the fact that the difference between the ideal cycle and the real one consists in the irreversibilities met in the components. From these, only $30 \%$ continued with the right comment. The rest were not able to comment at all.

Question 9: The increase in of the evaporation temperature leads to decrease of irreversibilities resulting the decrease of exergy losses in the components. For this reason, the exergy efficiency will increase. $90 \%$ of the students replied that if COP increases together with the evaporation temperature increase, it is normal to expect an improvement in the exergy efficiency values. The rest were not able to answer/ comment this question.

Question 10: $95 \%$ of the comments stated that the energy efficiency of the refrigeration plant is connected to the selection of the proper eco- friendly refrigerant, able to provide high values for COP and exergy efficiency, while the rest ignored the exergy efficiency.

\section{CONLUSIONS}

In order to provide on the working market professionals well trained in the field of energy efficiency specific to refrigeration plants, are needed efforts done by the lecturer and the students as well.

The main aspects of this topic- optimised isulation, search of new refrigerants, specific attention on compression systems and cooling systems, have to be rigorously debated during teaching activities. Still, a brief questionnaire submitted to the students at the end of the chapter dedicated to this technology is welcomed, when it is about assessing an intermediary knowledge evaluation.

The questions included in the questionnaire were clearly stated and reflected subjects discussed during theoretical and practical activities.

The comments provided by the students are encouraging, seen the statistics of their comments for each question. Still, there are aspects to be improved. It was seen that comments related to second law theory couldn't achieve a good score. The explanation might consist in the fact that students forgot this theory delivered a year before, or this theory was not well understood at the time when was delivered. On the other hand, it is true that concepts such as entropy, exergy, exergy destruction are quite delicate for students, this is why are needed more efforts in order to clarify them, at any moment.

For this reason, it is indicated to continue with this kind of interrogation as often is possible, by involving this concepts in the assessment of other technologies studied within the discipline Thermal Efficiency of Buildings and Industrial Processes.

\section{REFERENCES}

[1] Atmaca A., Atmaca N., 2018 , Energy efficiency and engineeering applications in conjunction with the International Energy and Engineering Conference 2016, Energ. Econ. Emvorion, Vol 3, No 1, pp 1-4.

[2] Twumasi E., Frimpong E., A., Appiah D., O., Okeyere P., Y., 2017 , Energy efficiency awareness and preparedness among students, IEEE PES-IAS Power Africa, pp 456-461.

[3] Pompea S., M., Walker C., E., 2020, The importance of pedagogical content knowledge in curriculum development for illumination engineering 14 th Conf on Education and Trening and Photonics: ETOP, Proc of SPIE, Vol 10452, pp 104526R-1-104526R-10

[4] Memet F., 2016, Comparative performance analysis of R134 $a$ and R290/R600a refrigerants in a vapor compression refrigeration cycle Journal of Marine technology and Environment, Vol 2, pp 31-34

[5] Hristov H., 2018 , Energy and environmental efficiency of industrial refrigeration installationsalysios, Acta Technica Corviniensis, Bulletin of Enfineering, Tome XI, Fascicule 3, pp 43-44 
Journal of Marine Technology and Environment Year 2021, Vol.1

[6] Ruiz V., 2012 , Analysis of existing refrigeration plants onboard fishing vessels and improvement possibilities Second Int Symposium of Fishing Vessel Energy Efficiency E-Fishing, Vigo, Spain Marine, 8 pp [7] Memet F., 2019 , A way to increase safety in marine refrigeration when using ammonia as a working agent CMU Annlas, Year XVIII, Vol 27, pp 37-40

[8] Memet F., 2020 , Energy and exergy analysis of a VCRS working with R600a within a thermodynamkc analysis IOP Conf SE.: Mater.Sci Eng. 916012066, pp 18 